NASA/CR-2002-211689

\title{
Low-Pressure Turbine Separation Control- Comparison With Experimental Data
}

Vijay K. Garg

University of Toledo, Toledo, Ohio 
Since its founding, NASA has been dedicated to the advancement of aeronautics and space science. The NASA Scientific and Technical Information (STI) Program Office plays a key part in helping NASA maintain this important role.

The NASA STI Program Office is operated by Langley Research Center, the Lead Center for NASA's scientific and technical information. The NASA STI Program Office provides access to the NASA STI Database, the largest collection of aeronautical and space science STI in the world. The Program Office is also NASA's institutional mechanism for disseminating the results of its research and development activities. These results are published by NASA in the NASA STI Report Series, which includes the following report types:

- $\quad$ TECHNICAL PUBLICATION. Reports of completed research or a major significant phase of research that present the results of NASA programs and include extensive data or theoretical analysis. Includes compilations of significant scientific and technical data and information deemed to be of continuing reference value. NASA's counterpart of peerreviewed formal professional papers but has less stringent limitations on manuscript length and extent of graphic presentations.

- TECHNICAL MEMORANDUM. Scientific and technical findings that are preliminary or of specialized interest, e.g., quick release reports, working papers, and bibliographies that contain minimal annotation. Does not contain extensive analysis.

- CONTRACTOR REPORT. Scientific and technical findings by NASA-sponsored contractors and grantees.
- CONFERENCE PUBLICATION. Collected papers from scientific and technical conferences, symposia, seminars, or other meetings sponsored or cosponsored by NASA.

- SPECIAL PUBLICATION. Scientific, technical, or historical information from NASA programs, projects, and missions, often concerned with subjects having substantial public interest.

- TECHNICAL TRANSLATION. Englishlanguage translations of foreign scientific and technical material pertinent to NASA's mission.

Specialized services that complement the STI Program Office's diverse offerings include creating custom thesauri, building customized data bases, organizing and publishing research results ... even providing videos.

For more information about the NASA STI Program Office, see the following:

- Access the NASA STI Program Home Page at http://www.sti.nasa.gov

- E-mail your question via the Internet to help@sti.nasa.gov

- Fax your question to the NASA Access Help Desk at 301-621-0134

- Telephone the NASA Access Help Desk at 301-621-0390

- Write to:

NASA Access Help Desk

NASA Center for AeroSpace Information 7121 Standard Drive

Hanover, MD 21076 
NASA/CR-2002-211689

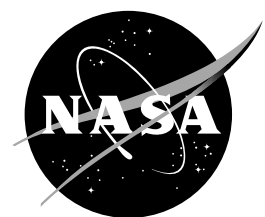

\section{Low-Pressure Turbine Separation Control- Comparison With Experimental Data}

Vijay K. Garg

University of Toledo, Toledo, Ohio

Prepared for the

Turbo Expo 2002

cosponsored by the American Society of Mechanical Engineers

and the International Gas Turbine Institute

Amsterdam, The Netherlands, June 3-6, 2002

Prepared under Contract NAS3-00180 and Cooperative Agreement NCC3-926

National Aeronautics and

Space Administration

Glenn Research Center 


\section{Acknowledgments}

The author wishes to thank Dr. Raymond Gaugler, Chief, Turbine Branch, at the NASA Glenn Research Center for his support of this work. Help from Dr. Richard Rivir of the Air Force Research Laboratory and Major Jeffrey Bons of the Air Force Institute of Technology regarding the experimental data is also gratefully acknowledged.

This report contains preliminary findings, subject to revision as analysis proceeds.

Trade names or manufacturers' names are used in this report for identification only. This usage does not constitute an official endorsement, either expressed or implied, by the National Aeronautics and Space Administration.

Available from

NASA Center for Aerospace Information 7121 Standard Drive

Hanover, MD 21076
National Technical Information Service 5285 Port Royal Road Springfield, VA 22100 


\title{
LOW-PRESSURE TURBINE SEPARATION CONTROL - COMPARISON WITH EXPERIMENTAL DATA
}

\author{
Vijay K. Garg* \\ University of Toledo \\ Toledo, Ohio 43606 \\ vijay.garg@grc.nasa.gov
}

\section{ABSTRACT}

The present work details a computational study, using the GlennHT code, that analyzes the use of vortex generator jets (VGJs) to control separation on a low-pressure turbine (LPT) blade at low Reynolds numbers. The computational results are also compared with the experimental data of Bons et al. [1] for steady VGJs. It is found that the code determines the proper location of the separation point on the suction surface of the baseline blade (without any VGJ) for Reynolds numbers of 50,000 or less. Also, the code finds that the separated region on the suction surface of the blade vanishes with the use of VGJs. However, the separated region and the wake characteristics are not well predicted. The wake width is generally over-predicted while the wake depth is under-predicted.

\section{NOMENCLATURE}

B jet blowing ratio $=(\rho u)_{\text {jet }} /(\rho u)_{\text {local }}$

$\mathrm{C}_{\mathrm{p}} \quad$ blade pressure coefficient $=\left(\mathrm{p}_{\mathrm{o}, \text { in }}-\mathrm{p}_{\mathrm{s}}\right) / 0.5\left(\rho \mathrm{u}^{2}\right)_{\text {in }}$

$\mathrm{C}_{\mathrm{x}} \quad$ axial chord of the blade

$\mathrm{d}$ injection hole diameter

$\mathrm{k} \quad$ turbulence kinetic energy

$\ell \quad$ turbulence length scale

$\mathrm{p}$ pressure

Pr Prandtl number

Re inlet Reynolds number $=C_{x}(\rho u / \mu)_{\text {in }}$

$\mathrm{Tu}$ freestream turbulence intensity

$\mathrm{u} \quad$ streamwise mean velocity

$\mathrm{v}^{*} \quad$ shear velocity

$\mathrm{x}, \mathrm{y}$ Cartesian coordinate system with origin at the blade leading edge

$\mathrm{y}^{+} \quad$ distance in wall coordinates $=\rho \mathrm{yv} * / \mu$

$\alpha \quad$ thermal diffusivity

$\Delta y \quad$ distance (from the wall) of the first point off the wall

$\varepsilon \quad$ turbulence dissipation rate

$\gamma \quad$ wake loss coefficient $=\left(\mathrm{p}_{\mathrm{o}, \text { in }}-\mathrm{p}_{\mathrm{o}, \mathrm{e}}\right) /\left(\mathrm{p}_{\mathrm{o}, \text { in }}-\mathrm{p}_{\mathrm{s}, \text { in }}\right)$

$\mu \quad$ dynamic viscosity

$\rho$ density

$\tau \quad$ shear stress

*NASA Resident Research Associate at Glenn Research Center. $\omega$ specific turbulence dissipation rate $=\varepsilon / \mathrm{k}$

\section{$\underline{\text { Subscripts }}$}

ef effective value

ex value at cascade exit

in value at cascade inlet

jet vortex generator jet conditions

$\ell \quad$ laminar value

local local blade mid-channel conditions

o stagnation value

s static value

$\mathrm{t}$ turbulent value

w value at the wall

\section{INTRODUCTION}

For the flow over an airfoil, there is an adverse pressure gradient region over a large part of the suction surface. This can cause the flow to separate on the suction surface, especially at low Reynolds numbers, in which case the boundary layer over the blade may be laminar. It is well known that a laminar boundary layer can withstand only a minor adverse pressure gradient before separation while a turbulent boundary layer can withstand a much stronger adverse pressure gradient region. Flow separation reduces lift and increases drag. It is thus undesirable and needs to be controlled.

Flow separation can be controlled by both passive and active techniques. The former employs small vortex generators (rectangular or delta shaped winglets) which are imbedded in a boundary layer ahead of a line of flow separation [2]. Spanwise arrays of vortex generators are often placed along a wing upstream of the flap hinge or inside the lip of a jet engine inlet diffuser. The longitudinal vortices generated in the boundary layer increase cross-stream mixing of streamwise momentum and suppress or eliminate separation. These fixed vortex generators have the advantages of simplicity, ruggedness and low cost. However, they add parasitic drag in flow situations where separation control is not needed, e.g., take-off and landing. 
In one of the active techniques, small jets blown through holes in the solid surface can generate longitudinal streamwise vortices in a boundary layer. These vortices increase cross-stream mixing of streamwise momentum. The surface holes are pitched an angle to the surface (generally low pitch angle of $30-45^{\circ}$ ), and inclined relative to the main flow direction (skew angle varying from $45-90^{\circ}$ ), much like the compound-angled holes on the shower-head of film-cooled blades. This method is called the vortex generator jet (VGJ) method. This method was first examined by Wallis [3, 4], and by Wallis and Stuart [5] primarily for the purpose of delaying shock-induced separation of turbulent boundary layers. Ball [6] employed VGJs alone and together with fixed generators for stall suppression in inlet diffusers of jet engines. Henry and Pearcey [7] show clearly the development of a single, dominant vortex for a VGJ at high skew angles. It has been shown by Johnston and Nishi [8] that this vortex energizes the separating boundary layer by bringing high momentum freestream fluid down to the wall. Experimental data on the beneficial effects of VGJs are available in [9].

The flow requirements for the jets in the VGJ method is a very small fraction of the total jet engine flow, and compressor bleed air is sufficient to power the system. The jets can be turned on and off as desired. With jets off, there is no parasitic drag. The potential applications of the VGJ method are numerous for external flow over aircraft and missiles. Internal flows in diffusers can also be improved and pressure losses reduced. The VGJ method can be used with appropriate flow direction sensors and a feedback control system to suppress surge and rotating stall in compressors of jet engines.

The operating Reynolds number for the low-pressure turbine in an aircraft gas turbine engine can drop below 25,000 during high altitude cruise. At such low Reynolds numbers, the boundary layers on the LPT blades are largely laminar, making them highly susceptible to flow separation near the aft portion of the blade suction surface, with associated increase in losses and drop in performance. Altering the blade shape to avoid this low Reynolds number separation problem is not feasible since such a modification will likely impair the engine operation at higher (design) Reynolds numbers. As such, an active flow control strategy, such as the use of VGJs, has been tested experimentally at the Air Force Research Laboratory recently [1, 10]. This paper aims to use the Glenn-HT code in order to analyze the use of VGJs at low Reynolds numbers, and to compare the computational predictions with the experimental data of Bons et al. [1].

\section{ANALYSIS}

The numerical simulation has been performed using the NASA Glenn Research Center General Multi-Block Navier-Stokes Convective Heat Transfer code, Glenn-HT. Briefly, the code, formerly known as TRAF3D.MB [11], is an explicit, multigrid, cell-centered, finite volume code with a $k-\omega$ turbulence model without any wall functions. This is a general purpose flow solver designed for simulations of flows in complicated geometries. The Navier-Stokes equations in a rotating Cartesian coordinate system are mapped onto a general body-fitted coordinate system using standard techniques. The multistage RungeKutta scheme developed by Jameson et al. [12] is used to advance the flow solution in time from an initial approximation to the steady state. A spatially varying time step along with a CFL number of 4 is used to speed convergence to the steady state. Eigenvalue-scaled artificial dissipation and variable-coefficient implicit residual smoothing are used along with a full-multigrid method. The overall accuracy of the code is second order. No wall functions are used, thus avoiding any bias to the complex three-dimensional flow structures near the blade or any other surface. While the Glenn-HT code is basically a compressible code, the present problem involves incompressible flow at rather low Reynolds numbers. Thus, there were some questions regarding the use of Glenn-HT code in such a situation. Needless to say, such questions about getting converged solution from the Glenn-HT code for such a case have been put to rest. How these results compare with experimental data is another matter.

While the Glenn-HT code has the original $k$ - $\omega$ model [13], the shear stress transport (SST) model of Menter [14], and the $k-\omega$ model of Wilcox [15] were implemented in it by Garg and Ameri [16]. The SST model encompasses both the $k-\omega$ and the $k$ - $\varepsilon$ models, with the original $k$ - $\omega$ model of Wilcox [13] activated in the near-wall region and the standard $k-\varepsilon$ model [17] activated in the outer wake region and in free shear layers. Moreover, the definition of eddy viscosity is modified to account for the transport of the principal turbulent shear stress. The reader is referred to Menter [14] for an elucidating discussion of the SST model. More details on the relevant equations and their implementation are available in Garg and Ameri [16]. The SST model was used for the present computations.

It is assumed that the effective viscosity for turbulent flows can be written as

$$
\mu_{e f}=\mu_{\ell}+\mu_{t}
$$

where the laminar viscosity $\mu_{\ell}$ is calculated using a power-law for its dependence on temperature [18]. The turbulent viscosity $\mu_{\mathrm{t}}$ is computed using the SST model. The turbulent thermal diffusivity is computed from

$$
\alpha_{t}=\frac{\mu_{t}}{\rho P r_{t}}
$$

where a constant value of 0.9 is used for the turbulent Prandtl number, $\operatorname{Pr}_{\mathrm{t}}$.

\section{$\underline{\text { Boundary Conditions }}$}

At the main flow inlet boundary located at an axial distance equal to the blade axial chord upstream of the blade leading edge, the total temperature, total pressure, whirl, and meridional flow angle are specified, and the upstream-running Riemann invariant based on the total absolute velocity is calculated at the first interior point and extrapolated to the inlet. The velocity components are then decoupled algebraically, and the density is found from total temperature, total pressure and total velocity using an isentropic relation. For the turbulence model, the value of $k$ and $\omega$ is specified using the experimental conditions, namely

$$
k=1.5\left(u_{i n} T u_{i n}\right)^{2}, \quad \omega=k^{1 / 2} / \ell,
$$

where $T u_{\text {in }}$ is the intensity of turbulence at the inlet (taken to be 0.01 as per experimental data for the PakB blade), $u_{\text {in }}$ is the absolute velocity at inlet, and $\ell$ is the integral length scale representing the size of the energy containing eddies. This length scale needs to be assumed, if not reported as part of the experimental conditions, as in the present case. It was assumed to be $5 \%$ of the blade axial chord.

At the main flow exit plane located at an axial distance equal to $80 \%$ of the blade axial chord downstream of the blade trailing edge, 
the static pressure is specified and the density and velocity components are extrapolated from the interior. At the solid surface of the blade, the no-slip condition is enforced, and temperature is specified as per experimental data. The boundary conditions for turbulence quantities on the walls are $k=0$, and

$$
\omega=\left.100 \frac{\partial u}{\partial y}\right|_{\text {wall }}
$$

for a hydraulically smooth surface. An upper limit is imposed on the value of $\omega$ at the wall, as suggested by Menter [19] and found effective by Chima [20],

$$
\left(\omega_{\max }\right)_{\text {wall }}=\frac{800}{\operatorname{Re}} \frac{v}{(\Delta y)^{2}}
$$

The grid around the blade extends to mid-way between two adjacent blades with periodic flow conditions in terms of cylindrical velocity components set on a dummy grid line outside this boundary. For a linear cascade (which is true for the experimental data), it is possible to consider only a slice of the real span for computational purposes with a periodic boundary condition at both ends of the computational span. For the basic blade with no VGJ, this slice can be of any reasonable width, but with VGJs, the width of the slice is one span-wise pitch of the holes.

The effect of VGJs has been incorporated in the form of appropriate boundary conditions at the hole locations on the blade surface. Each hole exit in its true oval shape is represented by 224 control volumes. Different velocity and temperature profiles for the injected fluid can be specified at the hole exits. For the present study, polynomial distribution [21] of velocity and temperature of the injectant at the hole exit was specified. The injectant angle was taken to be the same as the hole angle. Turbulent intensity at the hole exit was assumed to be $1 \%$ (same as for the freestream), while the turbulence length scale at the hole exit was taken to be the same as the hole diameter $d$.

\section{EXPERIMENTAL DETAILS}

Measurements were made by Bons et al. [1] in an induction wind tunnel at the U.S. Air Force Research Laboratory. The linear cascade consisted of eight $0.88 \mathrm{~m}$ (34.5 in) span, $0.18 \mathrm{~m}$ (7 in) axial chord $\left(C_{\mathrm{x}}\right)$ blades plus two partial blade endwalls. The blades were fabricated from molded polyurethane resin. The 2-D blade shape studied is the Pratt \& Whitney "PakB" research design, which is a Mach number scaled version of a typical highly loaded LPT blade design. The cascade had a solidity (axial chord to blade spacing) of 1.13, an inlet flow angle of $55^{\circ}$ (measured from the plane of the cascade), and a design exit angle of $30^{\circ}$. Blades 4 and 6 were instrumented around both pressure and suction surfaces (in the center $0.2 \mathrm{~m}$ of their span) with forty $1 \mathrm{~mm}$ diameter static pressure taps. Uncertainties in the pressure measurement translated to an error of \pm 0.18 in the $C_{p}$ data at $\operatorname{Re}=100,000[1]$.

Blade \#5 of the cascade had the active separation control. It was manufactured with a hollow cavity running the span of the blade and covering the region from $40 \%$ to $90 \%$ axial chord. A needle valve located upstream of the feed port allows fine control of the mass flow rate into the blade cavity. Air exhausts from this valve into a $1.2 \mathrm{~cm}$ diameter capped copper tube running the span of the blade inside the cavity. Holes of $1.5 \mathrm{~mm}$ diameter and spaced every $2.54 \mathrm{~cm}$ along the copper tube produced an even distribution of air flow to the VGJs. The $1 \mathrm{~mm}$ diameter $(d)$ cylindrical VGJ holes were drilled from the exterior surface of the blade, through the $4 \mathrm{~mm}$ thick wall, and into the cavity with a $30^{\circ}$ pitch angle and a $90^{\circ}$ skew angle. The VGJ holes have a length of $8 d$ and are spaced every $10 d$ along the center $0.46 \mathrm{~m}$ of this blade span. The row of VGJs was placed at $0.73 \mathrm{C}_{\mathrm{x}}$. This location is within the separated region on the baseline, uncontrolled blade at a Reynolds number of 50,000 [1]. The jet blowing ratio $(B)$ was computed as the ratio of the jet exit velocity to the local freestream velocity as calculated from the local pressure coefficient. While the inlet Reynolds number was varied between 25,000 and $100,000, B$ was taken as $0,1,2$ or 4 .

Standard pitot and hot-wire probes mounted on a large Dantec 3axis traverse located atop the tunnel facility were used to map a $0.6 \mathrm{~m}$ $\times 0.6 \mathrm{~m}$ planar cross-section of the flow domain. Wake velocity profiles were measured using a single $4 \mu \mathrm{m}$ diameter tungsten hot-wire. A single TSI sub-miniature hot-film probe was used for boundary layer profile measurements. The hot- film sensor diameter was $25 \mu \mathrm{m}$ and the sensing element length was $0.25 \mathrm{~mm}$. The error in the hot-wire and film probes was within $\pm 2 \%$ at flow rates of interest. More details are available in [1].

\section{COMPUTATIONAL DETAILS}

The computational span extended over a part of the blade span with a periodic boundary condition at both ends. In the axial direction, the computational domain extended from the inlet plane located one axial chord upstream of the blade leading edge to the exit plane located $80 \%$ of the axial chord downstream of the blade trailing edge. Around the blade, the grid extends to mid-way between two adjacent blades with periodic boundary conditions. Figure 1 shows a spanwise section of the multi-block viscous grid around the blade. The viscous grid is obtained from an inviscid grid by clustering the grid near all the solid walls (blade here). The clustering is done in such a way as to ensure that in the viscous grid, the distance of any cell center adjacent to a solid wall, measured in wall units $\left(y^{+}\right)$, is less than half for the cases studied here, following Boyle and Giel [22]. The inviscid grid was generated using the commercial code GridPro/az3000 [23]. For computational accuracy the ratio of two adjacent grid sizes in any direction was kept within 0.8-1.25. As can be observed from Fig. 1, the grid quality is very good especially near the blade surface. Figure 1 also shows the grid over the blade span near and within the injection hole exits.

Initially, the grid for the blade with injection holes consists of 136 blocks but before the solver is used, it can be merged into just 10 blocks using the Method of Weakest Descent [24]. The final viscous grid consists of 160128 cells, formed by clustering near the blade from an inviscid grid with 92928 cells. There are 224 cells within the hole exit on the blade surface. The inviscid grid has 144 cells around the blade (for the O-grid around the blade), 28 cells in the blade-to-blade direction from the blade to the periodic boundary in-between the two blades, and 24 in the spanwise direction. After clustering, the number of cells in the blade-to-blade direction increases to 48 . Two more grids were generated for a grid-independence study. One inviscid grid had 1.5 times the number of cells in each direction as compared to the basic grid described above. For the second grid, the basic inviscid grid was clustered near the blade with a grid spacing half of that for the basic viscous grid. All these variations of the basic grid yielded nearly the same values for the skin friction coefficient on the entire blade surface as the basic grid; any variations were within $\pm 2 \%$. The results presented here correspond to the basic grid shown in Fig. 1. 
Computations were run on the 16-processor C90 supercomputer at NASA Ames Research Center. The code requires about 26 million words of storage with all blocks in memory for the case with injection, and takes about $7 \mathrm{~s}$ per iteration for two levels of multi-grid. A case requires about 4000 iterations to converge for a case with injection. This unusually large number of iterations for convergence is due to the computation of incompressible flow at low Reynolds numbers. Recalling that the Glenn-HT code is essentially a compressible code, the code was initially run to near-convergence for one case with and without injection for an exit Mach number of 0.6. The exit Mach number was then subsequently reduced in steps of 0.1 to a final value of 0.2 , which is essentially an incompressible flow condition. This obviated the use of any low Mach number preconditioning. For subsequent cases, results for this case served as the starting point.

\section{RESULTS and DISCUSSION}

Several experimental cases for the PakB blade, available in [1], were analyzed for comparison. These cases cover three inlet Reynolds number values, 25000, 50000 and 100000 for a freestream turbulent intensity of $1 \%$. Most of the data in [1] are for $\mathrm{Tu}=1 \%$. Values of $B$ for which computations were done are 0,1 and 2. Figure 2 shows the computed shear stress on the basic blade surface, without any VGJ, for three values of the inlet Reynolds number. In this figure, the zero shear stress line is shown for reference. Clearly, the shear stress is negative beyond the separation point on the suction surface of the blade. The separation point on the suction surface, corresponding to $\tau_{\mathrm{w}}=0$, is little affected by the Reynolds number; it is at $0.71 \mathrm{C}_{\mathrm{x}}$ for $\mathrm{Re}$ $=50,000$ and 100,000 , but at $0.73 C_{x}$ for $\operatorname{Re}=25,000$. There appears to be a small region on the pressure surface as well that has separated flow for Reynolds numbers $\geq 50,000$. The small separated region on the pressure surface is over $0.22 \leq x / \mathrm{C}_{\mathrm{x}} \leq 0.25$ for $\mathrm{Re}=50,000$, and over $0.18 \leq x / C_{x} \leq 0.29$ for $\operatorname{Re}=100,000$. There is no separated region over the pressure surface for $\mathrm{Re}=25,000$. The location of separation point on the suction surface matches very well with the experimental data [25] for Reynolds numbers of 50,000 or less. Bons et al. [1] give no indication whether they observed any separated region over the pressure surface.

We may note that the boundary layer over the entire blade is laminar, as evidenced in Fig. 3. This figure shows the dimensionless turbulent viscosity, $\mu_{t}$, within a narrow range from 0 to 1.0 in the flow field for $\mathrm{Re}=50,000$ and $\mathrm{B}=0$ and 1 . Noting that the dimensionless laminar viscosity, $\mu_{\ell}$, is nearly unity (dimensionless local temperature is near unity), it is clear that the effective viscosity within the entire boundary layer over the blade surface is essentially laminar. We may note the presence of separation on the suction surface in Fig. 3(a), while with the VGJs turned on, the flow gets attached (cf. Fig. 3(b)). Similar results were obtained for $\operatorname{Re}$ of 25,000 and 100,000 .

Figure 4 shows the velocity vectors, colored by static pressure, in the flow field around the blade for inlet Reynolds number of 50,000, and for $\mathrm{B}=0$ and 1 . The thick separated region, with reverse flow, is clearly visible in Fig. 4(a) for the uncontrolled blade, while there is almost no separation on the suction surface for the controlled blade (Fig. 4(b)) with $B=1$. On the pressure surface, the velocity profiles appear to be close to separation over a very small region, as discussed above regarding the results in Fig. 2. Similar results were obtained for Re of 25,000 and 100,000.

Figure 5 compares the present computations with the experimental data [1] for the pressure coefficient on the baseline blade at two inlet
Reynolds numbers and $\mathrm{Tu}=1 \%$. The comparison is very good on the pressure surface but not so good on the suction surface due to the presence of separation. While the experimental data exhibit the classic plateau indicating non-reattaching laminar separation, the analysis predicts significant diffusion through the separation region. Similar discrepancy was observed by Bons et al. [1] between their experimental data and the 2-D Navier-Stokes Vane Blade Interaction (VBI) code.

Figure 6 compares the computed boundary layer profiles over the baseline (no VGJ) blade suction surface at three chordwise locations with the experimental data from Bons et al. [1] for $\operatorname{Re}=50,000$ and $\mathrm{Tu}=1 \%$. At $67 \%$ axial chord, the experimental profile was noted by Bons et al. [1] to be unsteady in the region $y<3 \mathrm{~mm}$. That is why the experimental data fall into a wide band in the near-wall region. At $73 \%$ and $79 \%$ axial chord, the flow is separated, with the computations clearly showing reverse flow. For the experimental data, reverse flow direction could not be resolved [1] since a single hot-film probe was used. However, separate smoke visualization did confirm that flow reversal was present inside the separation bubble at the $73 \%$ axial chord measurement station. The comparison between the computed and experimental data is not very good, specially at $79 \%$ axial chord location, where the experimental data show much thicker boundary layer compared to the computations. This implies that the separated region is not well resolved by the computations.

A similar comparison is shown in Fig. 7 for inlet Reynolds number $=100,000$ and $\mathrm{B}=0$. Clearly at this high Reynolds number, the boundary layer is thinner compared to that in Fig. 6. However, the experimental data show a thinner boundary layer compared to that from the computations at all three chordwise locations. While the computations show separated (reverse) flow at both $73 \%$ and $79 \%$ axial chord locations, Bons et al. [1] report that the flow was close to separation at the $79 \%$ axial chord location but attached at the $73 \%$ axial chord location. Figure 8 compares the computed velocity profiles in the wake at 0.62 axial chord downstream from the blade trailing edge for two inlet Reynolds numbers against the experimental data of Bons et al. [1] with no VGJ. While the computations show little effect of Re on the wake width and relatively small effect on the wake depth, the experimental data show a larger effect of $\mathrm{Re}$ on both the wake width and depth. At $\mathrm{Re}=50,000$, the computed and experimental wake widths match but the computed wake depth is only about half of the experimental value. At $\operatorname{Re}=100,000$, the computed wake depth compares well with the experimental value but the computed wake width is about twice that of the experimental value. Such problems with computed wakes are well known, and point to the need for more work in this area. Moreover, in the present case, these problems are augmented by the large separation region over the suction surface of the blade. Any unsteady effects owing to the flow separation and wake shedding cannot be resolved by the steady code that was used for the present computations.

Figure 9 shows a comparison between the presently computed loss coefficient, $\gamma$, and the experimental values provided by Bons et al. [10]. While the experimental data show a sudden drop in loss coefficient around $\operatorname{Re}=50,000$, the computations show only a gradual decrease in the loss coefficient from $\operatorname{Re}=25,000$ to 100,000 . This is again a reflection of the poor wake prediction noted above. Figure 10 compares the computed boundary layer profiles over the blade suction surface at three chordwise locations with the experimental data from Bons et al. [1] for $\operatorname{Re}=50,000$ and $\mathrm{B}=2$. Both the computations and experiment show no separation (reverse flow). However, the 
experimental data show steeper profiles than the computed results at all the stations, similar to the results in Fig. 7 for $\mathrm{Re}=100,000$ and no VGJ. Bons et al. [1] attribute the doubly-inflected (but attached) velocity profile at $79 \%$ axial chord station to the ultimate penetration depth of the vortex jets into the freestream. The computed results do not show any such anomaly.

Figure 11 compares the computed velocity profiles in the wake at 0.62 axial chord downstream from the blade trailing edge for an inlet Reynolds number of 50,000 against the experimental data of Bons et al. [1] with and without VGJs. We may note that the data corresponding to $\mathrm{B}=0$ are also available in Fig. 8; they are included here to compare with the data for $\mathrm{B} \neq 0$. The computed wake with VGJs on $(B \neq 0)$ is shallower and somewhat narrower than that without any VGJ $(B=0)$, as one would expect since the separation region vanishes when VGJs are on. However, the effect is not so dramatic, specially for the wake width, as for the experimental data. Experimentally the wake is very narrow when the VGJs are on compared to the case when they are not. The wake depth recovery, ratio of the wake depth for $\mathrm{B} \neq 0$ to that for $\mathrm{B}=0$, is about the same for both the computational and experimental data. Also, there is little difference between the profiles corresponding to $\mathrm{B}=1$ and $\mathrm{B}=2$ for both the computational and experimental data.

\section{CONCLUSIONS}

The Glenn-HT code was used to compute the flow over a lowpressure turbine blade at very low Reynolds numbers with and without the use of vortex generator jets. The results are compared with the experimental data of Bons et al. [1] for steady VGJs. It is found that the code determines the proper location of the separation point on the suction surface of the baseline blade (without any VGJ) for Reynolds numbers of 50,000 or less. Also, the code finds that the separated region on the suction surface of the blade vanishes with the use of VGJs. However, the separated region and the wake characteristics are not well predicted. The wake width is generally over-predicted while the wake depth is under-predicted. Thus, there is a need to improve the prediction of wake characteristics, especially in situations where large separated regions may exist upstream of the wake, as in the present case. For resolution of the unsteady effects due to flow separation and wake shedding, use of an unsteady code is recommended.

\section{REFERENCES}

1. Bons, J.P., Sondergaard, R. and Rivir, R.B., 1999, Control of Low-Pressure Turbine Separation Using Vortex Generator Jets, AIAA Paper 99-0367.

2. Pearcey, H.H., 1961, Shock Induced Separation and its Prevention, Boundary Layer \& Flow Control, vol. 2, (Ed.) G.V. Lachmann, Pergamon, NY, pp. 1170-1344.

3. Wallis, R.A., 1952, The Use of Air Jets for Boundary Layer Control, Aerodynamics Research Laboratories, Australia, Aero Note 110 (N-34736).

4. Wallis, R.A., 1960, A Preliminary Note on a Modified Type of Air Jet for Boundary Layer Control, Aeronautical Research Council, Australia, Current Paper No. 513.
5. Wallis, R.A. and Stuart, C.M., 1958, On the Control of ShockInduced Boundary-Layer Separation with Discrete Jets, Aeronautical Research Council, Australia, Current Paper No. 595 (N63-10138).

6. Ball, W.H., 1984, Tests of Wall Blowing Concepts for Diffuser Boundary Layer Control, AIAA Paper 84-1276.

7. Henry, F.S. and Pearcey, H.H., 1994, Numerical Model of Boundary Layer Control Using Air-Jet Generated Vortices, AIAA J., vol. 32, pp. 2415-2425.

8. Johnston, J.P. and Nishi, M., 1990, Vortex Generator Jets - Means for Flow Separation Control, AIAA J., vol. 28, pp. 989-994.

9. Compton, D.A. and Johnston, J.P., 1992, Streamwise Vortex Production by Pitched and Skewed Jets in a Turbulent Boundary Layer, AIAA J., vol. 30, pp. 640-647.

10. Bons, J.P., Sondergaard, R. and Rivir, R.B., 2001, The Fluid Dynamics of LPT Blade Separation Control Using Pulsed Jets, ASME Paper 2001-GT-190.

11. Steinthorsson, E., Ameri, A.A. and Rigby, D.L., 1997, TRAF3D.MB A Multi-Block Flow Solver for Turbomachinery Flows, AIAA Paper 97-0996.

12. Jameson, A., Schmidt, W. and Turkel, E., 1981, Numerical Solutions of the Euler Equations by Finite Volume Methods Using Runge-Kutta Time-Stepping Schemes, AIAA Paper 811259.

13. Wilcox, D.C., 1988, Reassessment of the Scale-Determining Equation for Advanced Turbulence Models, AIAA J., vol. 26, pp. 1299-1310.

14. Menter, F.R., 1994, Two-Equation Eddy-Viscosity Turbulence Models for Engineering Applications, AIAA J., vol. 32, pp. 15981605.

15. Wilcox, D.C., 1998, Turbulence Modeling for CFD, DCW Industries, 2nd Edn.

16. Garg, V.K. and Ameri, A.A., 2001, Two-Equation Turbulence Models for Prediction of Heat Transfer on a Transonic Turbine Blade, Int. J. Heat \& Fluid Flow, vol. 22, pp. 593-602.

17. Jones, W.P. and Launder, B.E., 1973, The Calculation of Low-Reynolds-Number Phenomena with a Two Equation Model of Turbulence, Int. J. Heat Mass Transfer, vol. 16, pp. 1119-1130.

18. Schlichting, H., 1979, Boundary Layer Theory, McGraw-Hill, New York, $7^{\text {th }}$ edition, pp. 312-313.

19. Menter, F.R., 1992, Improved Two-Equation $k$ - $\omega$ Turbulence Models for Aerodynamic Flows, NASA TM103975.

20. Chima, R.V., 1996, A $k-\omega$ Turbulence Model for Quasi-ThreeDimensional Turbomachinery Flows, AIAA Paper 96-0248.

21. Garg, V.K. and Gaugler, R.E., 1997, Effect of Velocity and Temperature Distribution at the Hole Exit on Film Cooling of Turbine Blades, J. Turbomachinery, vol. 119, pp. 343-351.

22. Boyle, R.J. and Giel, P., 1992, Three-Dimensional Navier Stokes Heat Transfer Predictions for Turbine Blade Rows, AIAA Paper 92-3068.

23. Program Development Corporation, 1997, "GridPro ${ }^{\mathrm{TM}} / \mathrm{az3000}$ User's Guide and Reference Manual," White Plains, NY.

24. Rigby, D.L., Steinthorsson, E. and Coirier, W.J., 1997, Automatic Block Merging Using the Method of Weakest Descent, AIAA Paper 97-0197.

25. Rivir, R.B., 2001, private communication. 


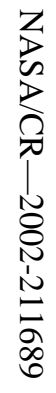

Fig. 1 Spanwise section of the multi-block viscous grid around the blade, with detail of grid over the blade span nea and within the hole exits

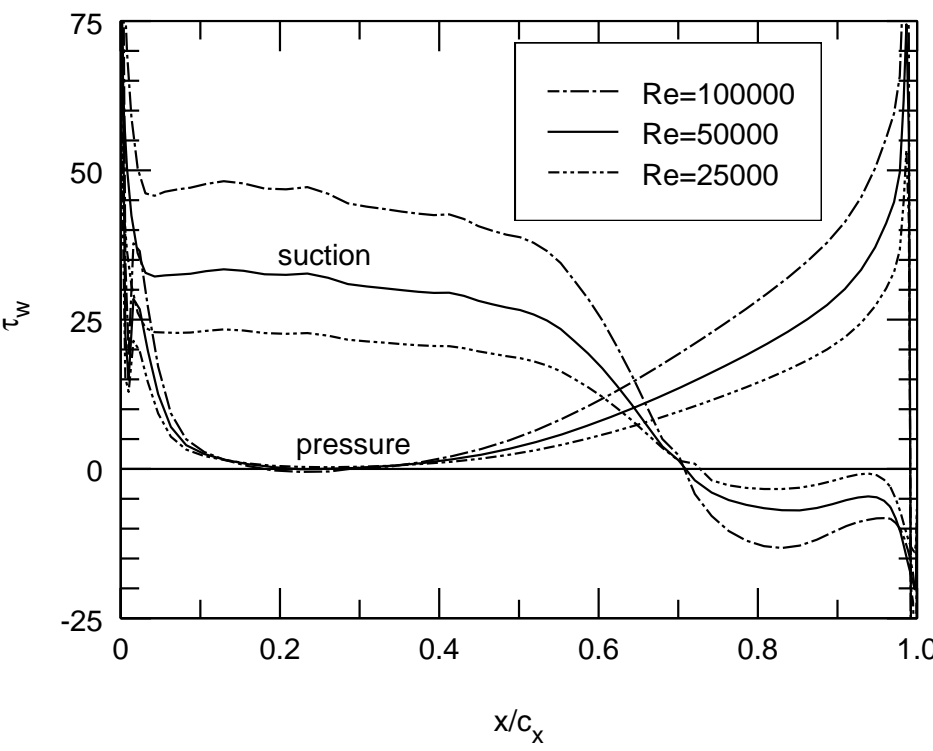

Fig. 2 Computed shear stress on the blade surface at various inlet Reynolds numbers $(\mathrm{Tu}=1 \% ; \mathrm{B}=0)$

periodic
boundary
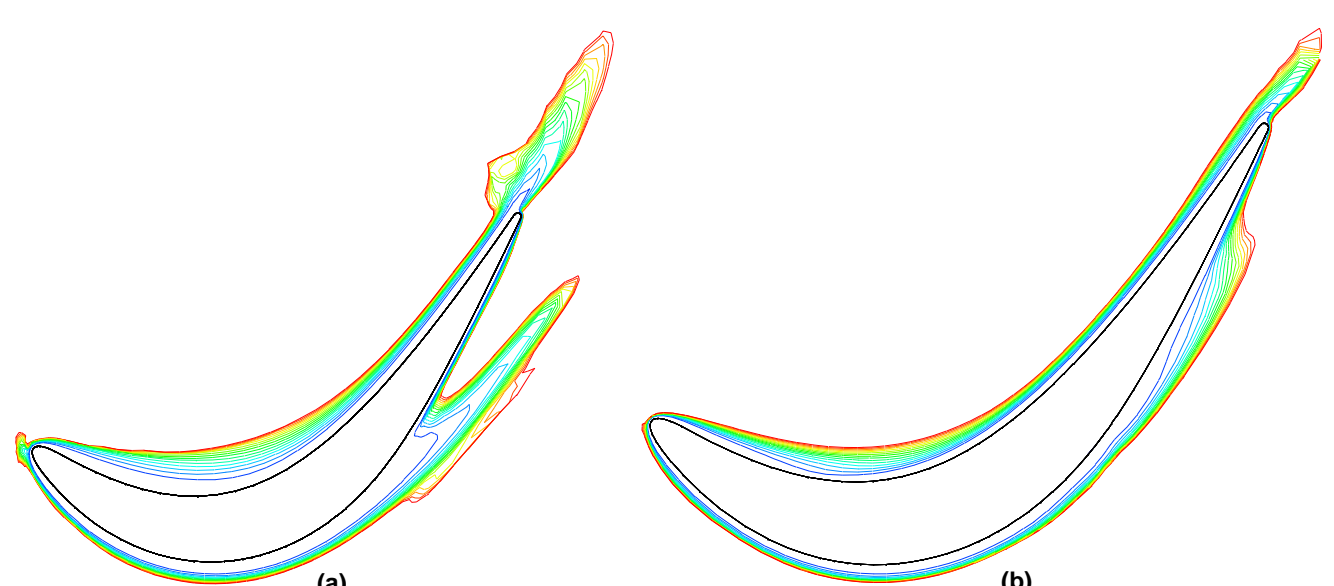

Fig. 3 Dimensionless turbulent viscosity within 0 and 1 in the flow field for $\mathrm{Re}=50,000 ; \mathrm{Tu}=1 \%$. (a) $\mathrm{B}=0$; (b) $\mathrm{B}=1$.

periodic
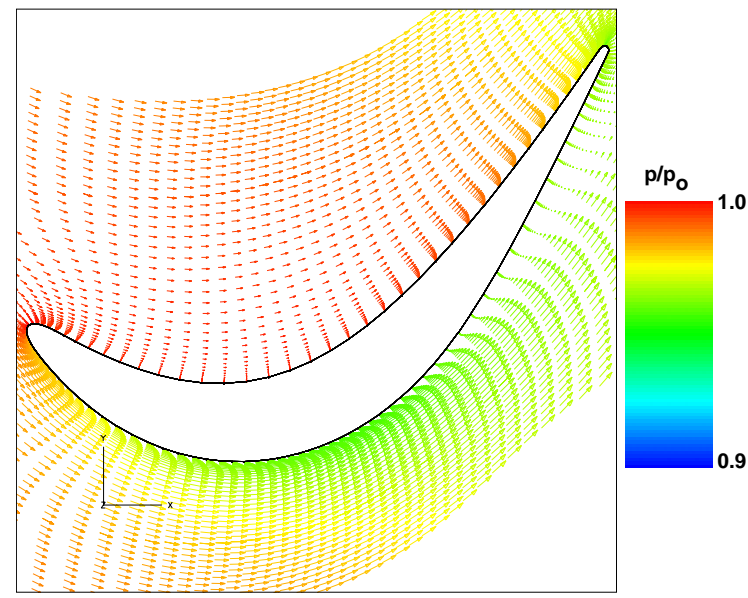

(a)

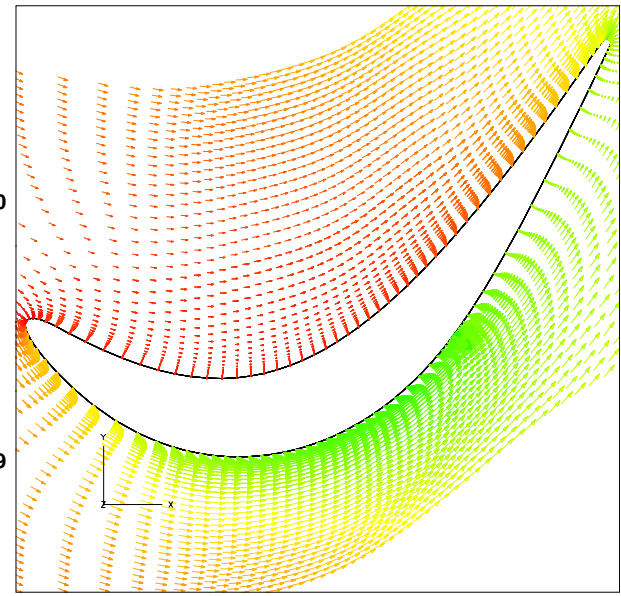

(b)

Fig. 4 Computed velocity vectors, colored by static pressure, around the blade for $\operatorname{Re}=50,000 ; \mathrm{Tu}=1 \%$. (a) $\mathrm{B}=0$; (b) $\mathrm{B}=1$.

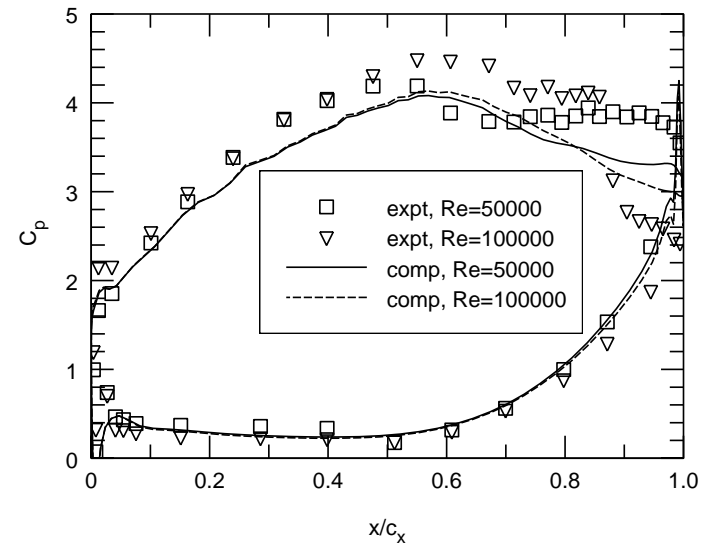

Fig. 5 Comparison of pressure coefficient for baseline blade at two inlet Reynolds 


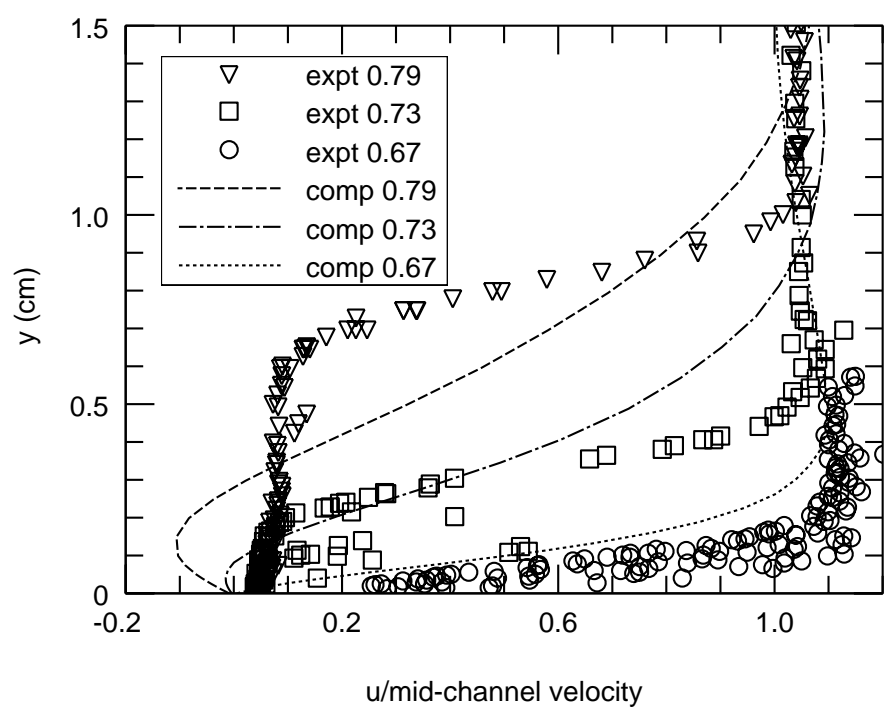

Fig. 6 Comparison of boundary layer profiles of streamline velocity normalized by mid-channel velocity at three chordwise stations: $0.67,0.73$ and 0.79 axial chord on the suction side.

$\mathrm{Re}=50,000 ; \mathrm{Tu}=1 \% ; \mathrm{B}=0$

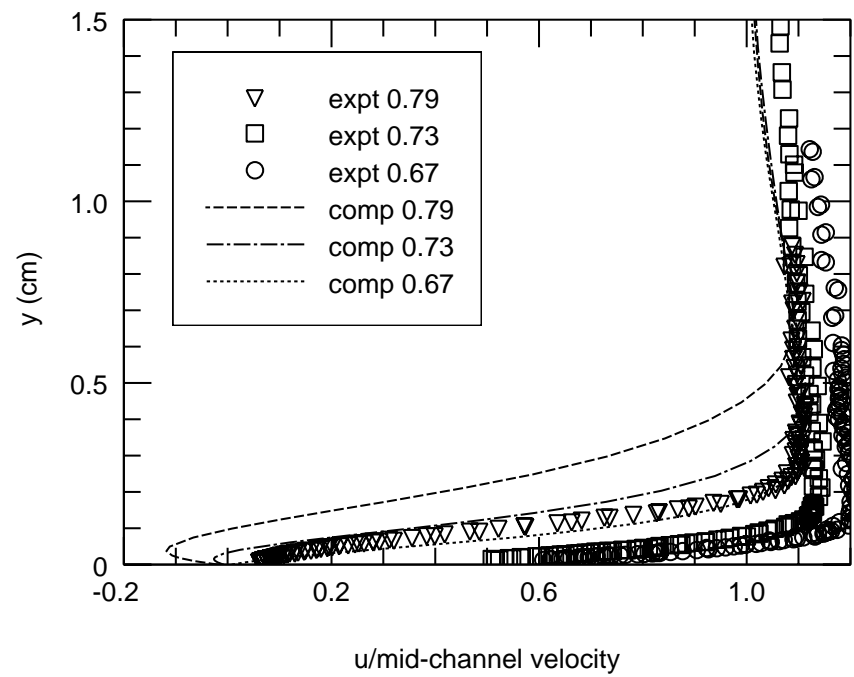

Fig. 7 Comparison of boundary layer profiles of streamline velocity normalized by mid-channel velocity at three chordwise stations: $0.67,0.73$ and 0.79 axial chord on the suction side. $\operatorname{Re}=100,000 ; \mathrm{Tu}=1 \% ; \mathrm{B}=0$

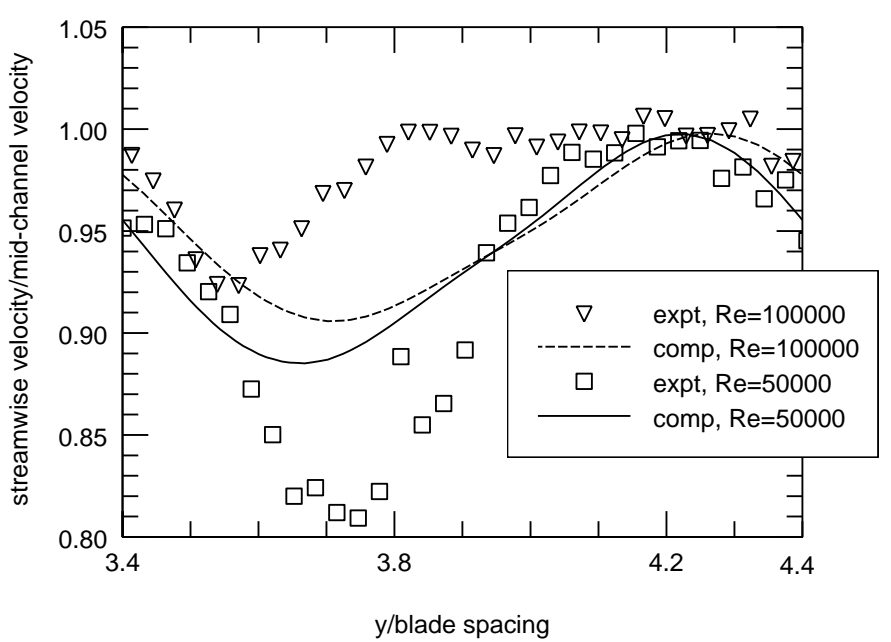

Fig. 8 Comparison of wake velocity profile at 0.62 axial chord downstream from the blade trailing edge for two inlet Reynolds numbers. $\mathrm{Tu}=1 \%$ and $\mathrm{B}=0$

NASA/CR-2002-211689

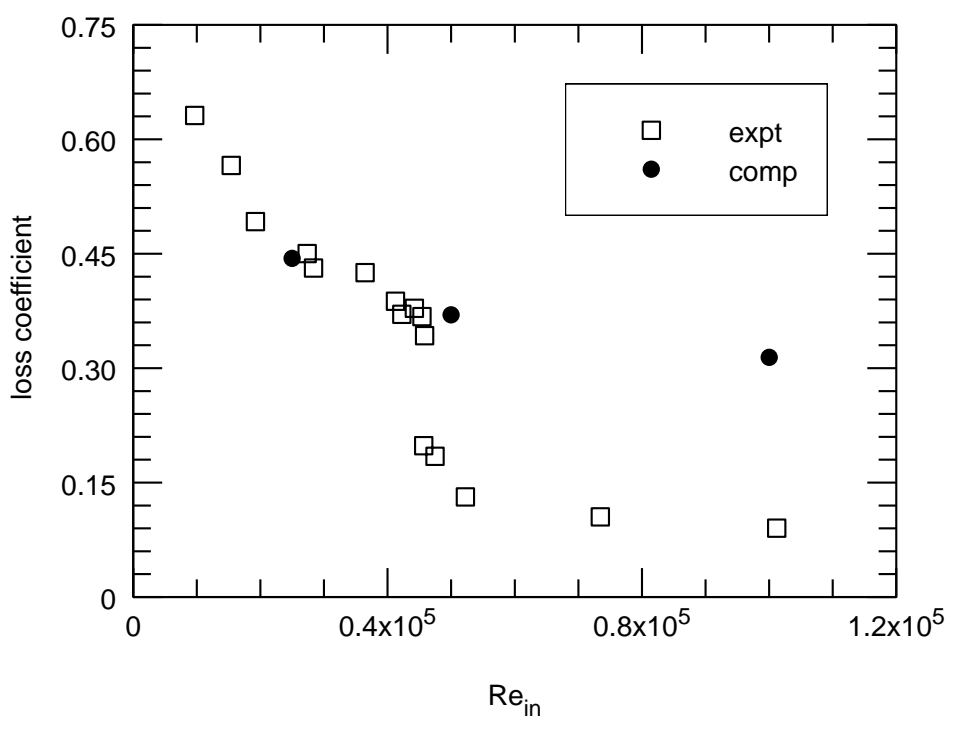

Fig. 9 Comparison of loss coefficient vs. inlet Reynolds number for Tu $=1 \%$

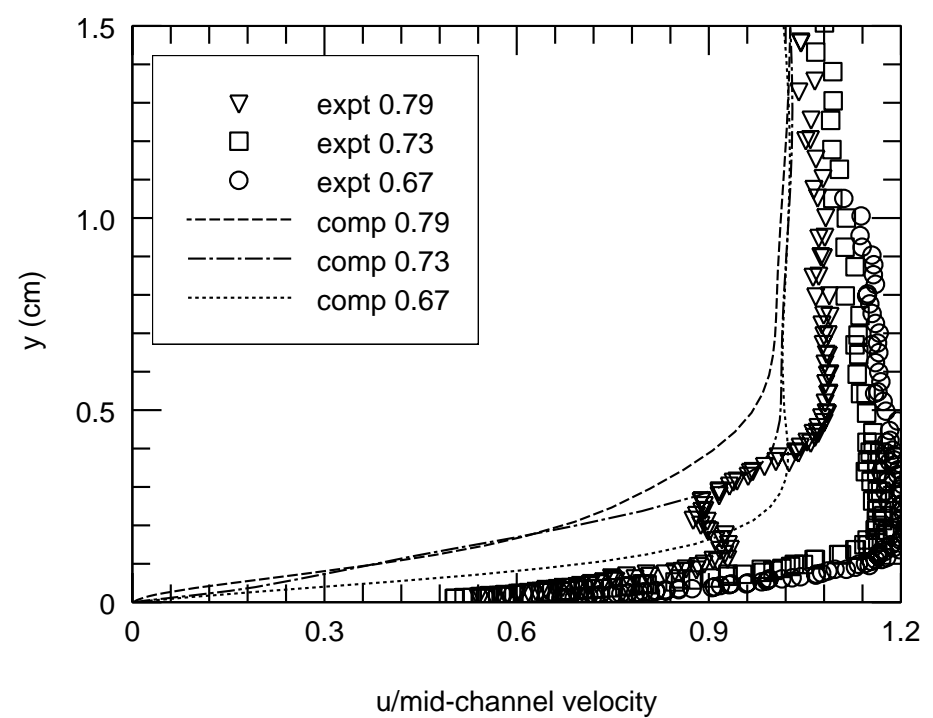

Fig. 10 Comparison of boundary layer profiles of streamline velocity normalized by mid-channel velocity at three chordwise stations: $0.67,0.73$ and 0.79 axial chord on the suction side.

$\operatorname{Re}=50,000 ; \mathrm{Tu}=1 \% ; \mathrm{B}=2$

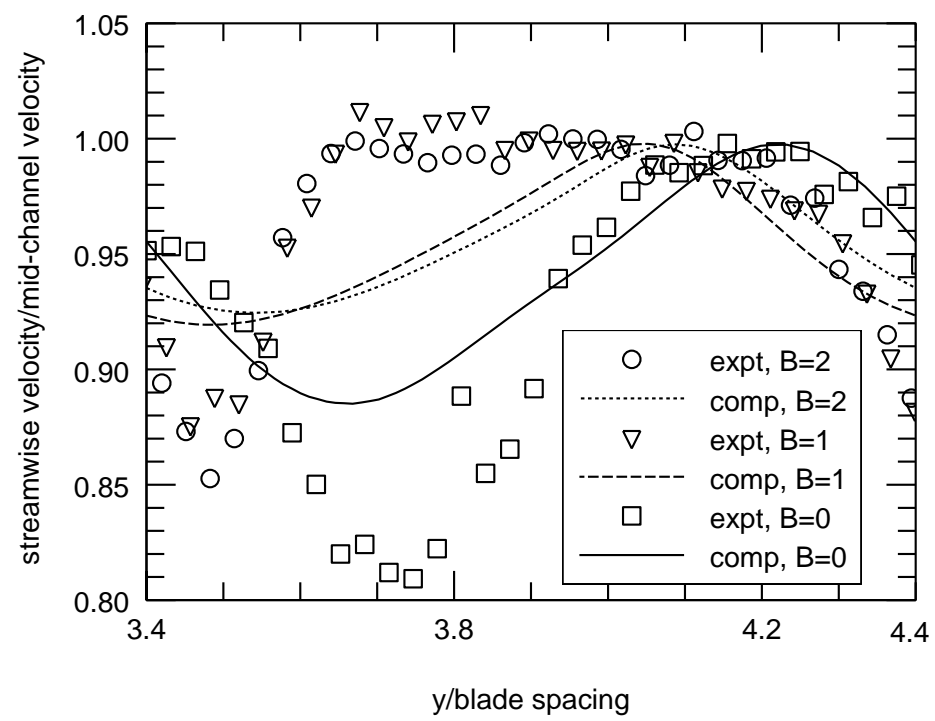

Fig. 11 Comparison of wake velocity profile at 0.62 axial chord downstream from the blade trailing edge for $R e=50,000 ; T u=1 \% ; B=0,1,2$ 


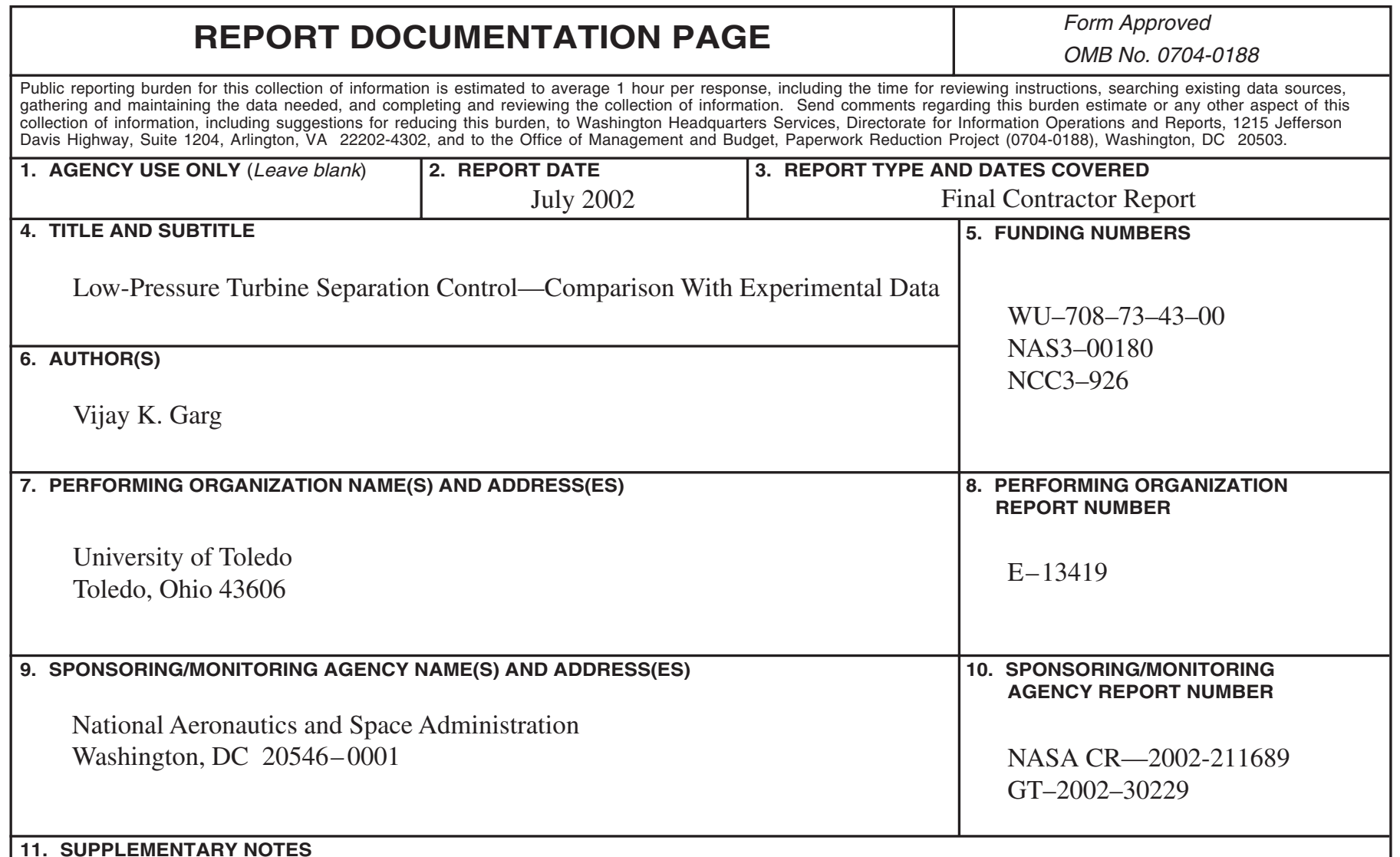

\section{SUPPLEMENTARY NOTES}

Vijay K. Garg, University of Toledo, Toledo, Ohio and NASA Resident Research Associate at Glenn Research Center. Prepared for the Turbo Expo 2002 cosponsored by the American Society of Mechanical Engineers and the International Gas Turbine Institute, Amsterdam, The Netherlands, June 3-6, 2002. Project Manger, R.E. Gaugler, Turbomachinery and Propulsion Systems Division, NASA Glenn Research Center, organization code 5820, 216-433-5882.

\begin{tabular}{|l|l|}
\hline 12a. DISTRIBUTION/AVAILABILITY STATEMENT & 12b. DISTRIBUTION CODE
\end{tabular}

Unclassified - Unlimited

Subject Categories: 07 and 34

Distribution: Nonstandard

Available electronically at http://gltrs.grc.nasa.gov/GLTRS

This publication is available from the NASA Center for AeroSpace Information, 301-621-0390.

13. ABSTRACT (Maximum 200 words)

The present work details a computational study, using the Glenn HT code, that analyzes the use of vortex generator jets (VGJs) to control separation on a low-pressure turbine (LPT) blade at low Reynolds numbers. The computational results are also compared with the experimental data for steady VGJs. It is found that the code determines the proper location of the separation point on the suction surface of the baseline blade (without any VGJ) for Reynolds numbers of 50,000 or less. Also, the code finds that the separated region on the suction surface of the blade vanishes with the use of VGJs. However, the separated region and the wake characteristics are not well predicted. The wake width is generally over-predicted while the wake depth is under-predicted.

14. SUBJECT TERMS 15. NUMBER OF PAGES

Low-pressure turbine; Separation control; Vortex generator jets 13

\begin{tabular}{|c|c|c|}
\hline $\begin{array}{c}\text { 17. SECURITY CLASSIFICATION } \\
\text { OF REPORT } \\
\text { Unclassified }\end{array}$ & $\begin{array}{c}\text { 18. SECURITY CLASSIFICATION } \\
\text { OF THIS PAGE } \\
\text { Unclassified }\end{array}$ & $\begin{array}{c}\text { 19. SECURITY CLASSIFICATION } \\
\text { OF ABSTRACT } \\
\text { Unclassified }\end{array}$ \\
\hline
\end{tabular}

NSN 7540-01-280-5500

Standard Form 298 (Rev. 2-89) 